\title{
Women's Role in Developing Economies: Case of Georgia
}

\author{
Nino Kharistvalashvili ${ }^{1}$
}

\begin{abstract}
The paper deals with the most topical gender issues in economic point of view and explains women's role in modern economy of developing country like Georgia.

In spite of the powerful process of the globalization and dissemination of ideas of human rights and gender equality huge problems related with gender inequality still remains and hinders the social and economic development of the societies.

The most prevalent issues regarding the abovementioned problem are the following: violence against women, pay gap between men and women workers, various stereotypes about the women existing in all over the world. All of these issues are dissected in an economic point of view.

Georgia is a post-soviet country with its peculiarities that are also reflected with respect to the gender issues and the analysis given in the paper considers these important characteristics.

In the modern world where women's role in social and economic life is continuously increasing the issues of gender equality gains an utmost importance.

Results of the study shows the ways for increasing women's involvement in the economic processes in the country and using women's skills and knowledge for the sake of the country.
\end{abstract}

Key words: Gender, equality, economy, pay gap, migration, unemployment.

\section{Introduction}

Women's' social-economical role has been frequently discussed. The attitudes by the culture are very different. Though it is not only culture, religion and stereotypes about women that lessened their worth.

Clearly it is difficult to solve gender related problems quickly and effectively at once. Since the beginning of $\mathrm{XX}$ century the idea of equality has been popularized systematically by the groups of different nature. In order to see the picture clearly we can compare different countries with each other by the specific index and find out that the best condition of human rights, equality, health and other variables are in Scandinavian countries (Forbes Georgia, 2014). In the end all these indexes are related to economic indicators and it turns out that countries with high economic growth and standard of living face less gender related or social problems. The road to Scandinavian nations is very long and difficult. However, experience exist that is shared by developed western states so there is no need to invent a bicycle. Though every nation has its typical social, cultural or religious different preferences. Given this reality, creating an effective system requires adapting to a specific space of international experience.

${ }^{1}$ Ivane Javakhishvili Tbilisi, State university, Georgia. 
Equal participation of women and men is very important for the democratic development process and also realization of gender equality principles. Originally "Gender" is English word, by means of state concept gender equality means: Culturespecific attitudes towards women's and men's behavior, personal characteristics, physical and intellectual capabilities. But, gender equality means the equal representation of women and men, authority, responsibility and participation in any private and public sector.

Women empowerment and economic development are closely related: in one direction, development alone can play a major role in driving down inequality between men and women; in the other direction, empowering women may benefit development (Duflo, 2012).

Like other developing countries, Georgia doesn't have definite attitude towards gender imbalance. State has Western values. In 2010, Parliament passed the Law on Gender Equality. Its essence is not allowing gender discrimination. The country has a law on public service, which turns men and women on equal terms. If we mention also new Labor Code it seems that in a legislative point of view everything is in order. But, unfortunately, the reality is beyond the regulations set by the law. For example, is 2013 Institute for Development of Freedom of Information (IDFI) conducted the research which offers the statistics of public service employees in terms of gender. According to the research of 165 public organization, $70.7 \%$ of employed are men and women are only represented by $29.3 \%$ (IDFI, 2013). This data is quite alarming. Especially under the circumstances when we know that the public sector offers much more competitive salaries and working conditions for citizens than the private sector or self-employment. This is the only space where wage policies are governed by low and discrimination by gender has no place. In other case women's labor costs more than twice as cheap as man's. Georgian National Statistics Service's information can be used as a proof for that. Women employees' average monthly salary is about 50\% less than men's (Geostat, 2013). The fact is if we consider it terms of gender, female labor is cheaper than male. Women are mainly employed in the private sector; they are also core of the country's well-being. The majority of men are employed in public sector. This is the space where the taxes paid by the citizens are distributed in the form of wages.

It is interesting how the population is distributed by its economic status. Only $57 \%$ of women are economically active and $78 \%$ of men. This statistics have a cause. $16 \%$ of economically inactive women are housewives (Forbes Georgia, 2014). Housewives' work is not qualified as economic activity so it is not estimated at any macroeconomic significance settings.

Developed countries absolutely change their attitudes toward the role of women in economy as well as in business. For example, according to the 2010 survey the countries where labor gender balance is ensured have a high rate of GDP (Forbes Georgia, 2014).

McKinsey's recent research that generates the results of 235 leading European companies and deals with women in leadership positions in the business field turned out that the performance of the companies where the gender balance of decision-making positions was policed created a critical mass (McKinsey\&Company, 2012). According to financial and corporate reporting the characteristics of women's behavior in the decision- 
making process has much more positive results than the decisions made by men in the same situation.

It is interesting what the trends are in this case in Georgia. How much do we considerate international experience, and if we are conductors of modern scientific evidences. For this purpose IBR conducted a survey in December 2013: "Women in decision-making positions". Survey that was carried out according to the results from twenty private sector fields and eighty companies showed that only $12.8 \%$ of women are represented in managerial positions. The study results are really bad, much worse than the public sphere. Georgia has the worst Gender Inequality Index results in the region and is in the $81^{\text {th }}$ place, while Azerbaijan occupies 54th place, Ukraine 59th place and Armenia is in the 57th (Forbes Georgia, 2014).

In the previous period of Georgia's economic crisis (1990) the magnitude of women's employment was very high and also in accordance with their role in economic life. After a short period, by the influence of political and social processes, the situation changed dramatically and if in 1989, 1 250, 0 thousand women were employed in the national economy by 2007 this figure amounted to only 812.2 thousand. (I.e. number of women employed decreased by 437.8 thousand). To assess the economic activity of women in the national economy in Soviet period it is important to discuss the rates of women's employment by separate sectors, where women's participation was particularly high (AYEG, 2009).

The transition to market economy conditions and economic changes caused by privatization changed significantly the structure of employment in the labor market, causing substantial amendments to the employment of women in areas and sectors of the economy.

According to the statistics during Soviet period 204 women out of 1000 had higher education, while this figure for men was 194 (AYEG, 2009).

Because of staying unemployed during a long period of time women lost their qualifications and became uncompetitive on labor market. This fact forced them to move to informal sector of economy where they work (if they get a job) without any safety and their right aren't protected on a workplace.

Women who have a job are faced with problems in balancing work life and care on their families. There are no supportive measures for them to solve this problem. This fact hinders professional development of women.

In contrast with women living in cities employment possibilities of women living in villages more constrained. There are no needed conditions for them to get proper knowledge and experience. They work hard within their families that include preparing meals, washing, cleaning, caring about children, work on farm and so on. They are not aware in their rights and hence for them it is complicated to fight for changing their lives. Very often they are isolated from the social life and have no opportunities for starting their own business and being involved actively in social and economic life.

Practice shows that women face with more problems in starting business that men do with regard to finding support from needed official or non-official structures, getting credit, finding business partner and so forth. In order to ensure higher involvement of women in business it is necessary to create favourable conditions that implies providing opportunities for professional trainings in business, starting and managing their own 
business, understanding their rights with regard to labor, tax, finances and economic issues.

Women's limited opportunities on labor market may be the reason for their unequal treatment within the family. Parents often anticipate more from their sons rather than from their daughters. And what is the bigger problem female teenagers also don't have high aspirations.

Ample research by psychologists shows that in developed countries, there is a widespread "implicit" bias, shared by both men and women, associating men with career and the sciences and women with family and liberal arts (Duflo, 2012).

In the Women's Economic Opportunity Index of 2012 released by The Economist Georgia showed result that is high than that of the world and the region.

According to the research women play important role in providing economic growth. Women's involvement in economic life has positive impact on GDP growth. Studies show that $25 \%$ of GDP growth from 1995 is stipulated by increased economic activity of women.

Georgia's position was 59th out of 128 countries. In order to move forward country should provide employment, finances, education and vocational training for women. Other important issue that must be addressed is legal and social status of women in society. According to the index Georgia performs better in this regard than its neighbours - Armenia, Azerbaijan, Russia and Turkey.

Below data are given on gender employment and salaries in business sector in 2012 (AYEG, 2014).

Table 1. Statistics on gender employment and salaries in business sector in 2012.

\begin{tabular}{|l|l|l|l|l|}
\hline & \multicolumn{2}{|l|}{ People employed (thousands) } & \multicolumn{2}{l|}{ Average monthly salary (GEL) } \\
\hline & Woman & Man & Woman & Man \\
\hline Georgia & 191,2 & 313,2 & 523,4 & 915,8 \\
\hline Large business & 97,8 & 187,8 & 687,5 & 1072 \\
\hline Medium business & 34,2 & 47,9 & 437,6 & 776,9 \\
\hline Small business & 59,3 & 77,5 & 281,5 & 569,3 \\
\hline
\end{tabular}

Source: Association of Young Economists of Georgia

In ministries in Georgia 78.6\% of employed people are men and only 21.4 are women. In local self-governments situation is a little bit better since women represent $32.5 \%$ of employed staff.

For the comparison reasons similar data can be shown for OECD and EU. At the regional level, women occupy 21.3 per cent of seats in parliament in the countries of the Organization for Security and Cooperation in Europe (OSCE), varying from 9.1 per cent in Turkey to 47 per cent in Sweden. Elsewhere, representation of women varies from 21.7 per cent in the Americas to 18.1 per cent in sub-Saharan Africa, 18 per cent in Asia, 13 per cent in the Pacific and 9.7 per cent in the Arab States (Inter-Parliamentary Union, 2009). Women ministers of the 27 States members of the European Union were found to hold portfolios relating to sociocultural functions ( 36.7 per cent), such as social affairs, health, children, family, youth, older people, education, science, culture and sports, rather 
than the economy (17.7 per cent)—finance, trade, industry and agriculture (European Commission, 2008a).

There are two rationales for supporting active policies to promote women. The first is that equity is valuable in and of itself: women are currently worse-off than men, and this inequality between genders is repulsive in its own right. For example, in the United Nation's 2005 report on the Millennium Development Goals (MDG), Kofi Annan, the Secretary General of the United Nations, writes: "The full participation of women to all levels of decision-making is a basic human right." The second, a central argument in the discourse of policymakers, is that women play a fundamental role in development. The gender gap in education, political participation, and employment opportunities should therefore be reduced not only because it is equitable to do so, but also because it will have beneficial consequences on many other society-wide outcomes. It should be done, in other words, to increase efficiency. Accordingly, in the same report, Kofi Annan argues that gender equality is in fact a "prerequisite" to achieving the other MDGs (Duflo, 2012).

\section{Conclusion}

Georgia as a post-Soviet developing country still have to do much in order to improve situation regarding gender equality and women's empowerment.

In order to achieve gender equality it is extremely important to provide sufficient access for them on economic and financial resources. It is also necessary for empowering women and for ensuring sustainable economic development. Supportive measures must be taken for increasing women's participation in economic decisionmaking.

Integrated policy should be developed in order to contribute to economic empowerment of women and for facilitating access to required resources. For this women's role in economic development should be fully recognized and understood. Economic and social development strategies should include women's involvement and their role must be defined clearly. Respective law enforcement measures also need to be taken in order to ensure that women's rights are protected as in the society as well as on the workplace.

\section{References}

AYEG, Woman and Business, 2009;

Forbes Georgia, №27, February, 2014;

European Commission, 2008a, Women and men in decision-making 2007: analysis of the situation and trends. Brussels: Directorate-General for Employment, Social Affairs and Equal Opportunities;

IDFI, Statistics of Public Servants in the Public Authorities of Georgia in terms of Gender, 2013;

Inter-Parliamentary Union (IPU) (2009). Women in the Parliament: situation as of 31 May 2009. Available at http://www.ipu.org/wmn-e/world.htm;

McKinsey\&Company, Women Matter 2012: Making the Breakthrough, 2012;

National Statistics Office of Georgia; 
United nations, Department of Economic and Social Affairs, Division for the Advancement of Women, "Women's Control over Economic Resources and Access to Financial Resources, including Microfinance, 2009 World Survey on the Role of Women in Development", 2009;

Women Empowerment and Economic Development, Esther Duflo, Journal of Economic Literature 2012, 50(4), 1051-1079. 